\title{
Prognostic models to predict survival in patients with advanced non-small cell lung cancer treated with first-line chemo- or targeted therapy
}

\author{
Rossana Berardi ${ }^{1}$, Silvia Rinaldi ${ }^{1}$, Matteo Santoni ${ }^{1}$, Thomas Newsom-Davis ${ }^{2}$, \\ Michela Tiberi $^{3}$, Francesca Morgese ${ }^{1}$, Miriam Caramanti ${ }^{1}$, Agnese Savini ${ }^{1}$, Consuelo \\ Ferrini $^{1}$, Mariangela Torniai ${ }^{1}$, Ilaria Fiordoliva ${ }^{1}$, Marc Bower ${ }^{2}$ and Stefano Cascinu ${ }^{1,4}$ \\ ${ }^{1}$ Clinica di Oncologia Medica, Università Politecnica delle Marche, Azienda Ospedaliero-Universitaria Ospedali Riuniti Umberto \\ I - GM Lancisi - G Salesi di Ancona, Ancona, Italy \\ ${ }^{2}$ Chelsea and Westminster Hospital, London, United Kingdom \\ ${ }^{3}$ Chirurgia Toracica, Università Politecnica delle Marche, Azienda Ospedaliero-Universitaria Ospedali Riuniti Umberto I - GM \\ Lancisi - G Salesi di Ancona, Ancona, Italy \\ ${ }^{4}$ Oncologia Medica-Università degli Studi di Modena e Reggio Emilia, Modena, Italy \\ Correspondence to: Rossana Berardi, email: rossana.berardi@libero.it
}

Keywords: lung cancer; neutrophil to lymphocyte ratio; platinum-base chemotherapy; prognosis; targeted therapy

Received: November 11,2015 Accepted: March 07, $2016 \quad$ Published: March 23, 2016

\section{ABSTRACT}

Background: We aimed to assess the prognostic role of neutrophilia, lymphocytopenia and the neutrophil-to-lymphocyte ratio (NLR), and to design models to define the prognosis of patients receiving first-line chemo- or targeted therapy for advanced non-small cell lung cancer (NSCLC).

Materials and Methods: We retrospectively analysed 401 consecutive patients with advanced NSCLC treated with first line chemo- or targeted therapy. Patients were stratified into two groups with pre-treatment NLR $\geq 3.7$ (Group A) vs. $<3.7$ (Group $B)$. The best NLR cut-off was identified by ROC curve analysis.

Results: At baseline 264 patients had NLR $\geq 3.7$ (Group A), whilst 137 had lower NLR (Group B). Median OS was 10.8 months and 19.4 months in the two groups $(p<$ $0.001)$, while median PFS was 3.6 months and 5.6 months, respectively $(p=0.012)$. At multivariate analysis, ECOG-PS $\geq 2$, stage IV cancer, non-adenocarcinoma histology, EGFR wild-type status and NLR were predictors of worse OS. Stage IV cancer, wild type EGFR status and NLR $\geq 3.7$ were independent prognostic factors for worse PFS. Patients were stratified according to the presence of $0-1$ prognostic factors $(8 \%)$, 2-3 factors (73\%) and 4-5 factors (19\%) and median OS in these groups was 33.7 months, 14.6 months and 6.6 months, respectively $(p<0.001)$. Similarly, patients were stratified for PFS based on the presence of 0-1 prognostic factor (15\%), 2 factors (41\%) and 3 factors (44\%). The median PFS was 8.3 months, 4.6 months and 3.3 months respectively $(p<0.001)$.

Conclusion: Pre-treatment NLR is an independent prognostic factor for patients with advanced NSCLC treated with first-line therapies.

\section{INTRODUCTION}

Lung cancer is the leading cause of cancer related death in both men and women [1]. Non-small cell lung cancer (NSCLC) accounts for approximately $85 \%$ of all lung cancers. NSCLC is often insidious, producing no symptoms until the disease is advanced. Over the past few years a variety of prognostic and predictive factors have been investigated in patients with NSCLC, and several prognostic models proposed to predict the outcome of patients with NSCLC after surgery [2-4] or chemotherapy and/or radiotherapy [5-6]. Despite this the prognosis for patient with advanced NSCLC remains dismal, and novel approaches are required in order to optimize patient outcomes and guide treatment decisions.

Inflammation contributes to the pathogenesis 
Table 1: Patient characteristics.

\begin{tabular}{|c|c|c|c|c|}
\hline Patients & $\begin{array}{l}\text { Overall } \\
401(\%)\end{array}$ & $\begin{array}{c}\text { NLR } \geq 3.7 \\
264(66)\end{array}$ & $\begin{array}{c}\text { NLR }<3.7 \\
137(34)\end{array}$ & $p$ \\
\hline $\begin{array}{l}\text { Gender } \\
\text { Male } \\
\text { Female }\end{array}$ & $\begin{array}{l}275(69) \\
126(31)\end{array}$ & $\begin{array}{c}180(68) \\
84(32)\end{array}$ & $\begin{array}{l}95(69) \\
42(31)\end{array}$ & 0.910 \\
\hline $\begin{array}{c}\text { Age, years } \\
\text { Range }\end{array}$ & $\begin{array}{c}68 \\
25-86\end{array}$ & $\begin{array}{c}66 \\
25-83\end{array}$ & $\begin{array}{c}68 \\
29-86 \\
\end{array}$ & 0.878 \\
\hline $\begin{array}{l}\text { ECOG-PS } \geq 2 \\
\text { ECOG-PS }<2\end{array}$ & $\begin{array}{c}35(9) \\
366(91)\end{array}$ & $\begin{array}{c}26(10) \\
236(90)\end{array}$ & $\begin{array}{c}15(11) \\
122(89)\end{array}$ & 0.732 \\
\hline $\begin{array}{l}\text { Histology } \\
\text { Adenocarcinoma } \\
\text { Squamous carcinoma } \\
\text { Other }\end{array}$ & $\begin{array}{l}258(64) \\
94(23) \\
49(13)\end{array}$ & $\begin{array}{l}166(63) \\
61(23) \\
37(14)\end{array}$ & $\begin{array}{l}92(67) \\
33(24) \\
12(9)\end{array}$ & 0.312 \\
\hline $\begin{array}{c}\text { Tumor Stage } \\
\text { Stage III } \\
\text { Stage IV }\end{array}$ & $\begin{array}{l}121(30) \\
280(70)\end{array}$ & $\begin{array}{c}81(31) \\
183(69)\end{array}$ & $\begin{array}{l}40(29) \\
97(71)\end{array}$ & 0.819 \\
\hline $\begin{array}{l}\text { EGFR mutation status } \\
\text { Wild-type } \\
\text { Mutated }\end{array}$ & $\begin{array}{c}360(90) \\
41(10)\end{array}$ & $\begin{array}{c}240(91) \\
24(9)\end{array}$ & $\begin{array}{c}120(88) \\
17(12)\end{array}$ & 0.839 \\
\hline $\begin{array}{l}\text { Smoking history } \\
\text { Former/current smoker } \\
\text { Never smokers }\end{array}$ & $\begin{array}{c}323(81) \\
78(19)\end{array}$ & $\begin{array}{l}211(80) \\
53(20)\end{array}$ & $\begin{array}{l}113(82) \\
24(18)\end{array}$ & 0.594 \\
\hline $\begin{array}{l}\text { Common sites of metastasis } \\
\text { Lung } \\
\text { Bone } \\
\text { Nervous system } \\
\text { Liver } \\
\end{array}$ & $\begin{array}{l}249(62) \\
161(40) \\
81(20) \\
74(18)\end{array}$ & $\begin{array}{l}182(69) \\
121(46) \\
61(23) \\
52(20)\end{array}$ & $\begin{array}{l}67(49) \\
40(29) \\
20(15) \\
22(16)\end{array}$ & 0.855 \\
\hline $\begin{array}{l}\text { First-line therapy } \\
\text { Platinum-based chemotherapy } \\
\text { Non platinum-based } \\
\text { EGFR-TKI }\end{array}$ & $\begin{array}{l}311(78) \\
62(15) \\
28(7)\end{array}$ & $\begin{array}{c}208(79) \\
38(14) \\
18(7)\end{array}$ & $\begin{array}{l}103(75) \\
24(18) \\
10(7)\end{array}$ & 0.687 \\
\hline $\begin{array}{l}\text { Response to first-line therapy } \\
\text { Partial response } \\
\text { Stable disease } \\
\text { Progressive disease }\end{array}$ & $\begin{array}{l}128(32) \\
134(33) \\
139(35)\end{array}$ & $\begin{array}{l}75(28) \\
88(33) \\
101(39)\end{array}$ & $\begin{array}{l}53(38) \\
46(34) \\
38(28)\end{array}$ & 0.053 \\
\hline Neutrophilia & $179(45)$ & $165(63)$ & $14(10)$ & $<0.001$ \\
\hline Lymphocytopenia & $87(22)$ & $85(32)$ & $2(1)$ & $<0.001$ \\
\hline
\end{tabular}

and progression of lung cancer. For example, chronic inflammatory lung diseases such as sarcoidosis and chronic obstructive pulmonary disease (COPD) are associated with a higher risk of lung cancer [7], whilst the chronic use of anti-inflammatory drugs seems to reduce the risk [8]. In vitro studies suggest that direct cell-cell interactions between neutrophils and NSCLC cells can induce the release of inflammatory mediators, which may promote tumor cell proliferation [9]. Indeed, NSCLC cells might secret immunoreactive IL-8 and stimulate polymorphonuclear neutrophils (PMNs) to release Arginase 1. Both molecules inhibit T-cell proliferation and favour tumor cell progression [10]. An elevated neutrophil count has been associated with poor prognosis in patients with NSCLC treated with chemotherapy, with a difference in overall survival (OS) of approximately 9 months compared to those with normal neutrophil count (19.3 vs. 10.2 months) [11].

Markers of inflammation, such as the neutrophilto-lymphocyte ratio (NLR), and their clinical significance in NSCLC patients are still under evaluation. NLR is an easily measurable parameter of systemic inflammation. Increased pre-treatment NLR has been demonstrated to be associated with poor outcome for various types of cancers including gastric cancer [12], advanced pancreatic cancer [13], hepatocellular carcinoma [14], colorectal 
Table 2: Univariate and multivariable analysis of predictors of OS in patients treated with first-line therapy for locally advanced or metastatic NSCLC.

\begin{tabular}{|c|c|c|c|c|}
\hline \multicolumn{5}{|c|}{ OVERALL SURVIVAL } \\
\hline & \multicolumn{2}{|c|}{ Univariate Cox Regression } & \multicolumn{2}{|c|}{ Multivariable Cox regression } \\
\hline & HR (95\%CI) & p-value & HR $(95 \% C I)$ & p-value \\
\hline Age $(\geq 70 y$ vs. $<70 y)$ & $1.13(0.88-1.45)$ & 0.336 & & \\
\hline Gender (F vs. M) & $0.67(0.51-0.88)$ & 0.005 & & \\
\hline ECOG-PS ( $\geq 2$ vs. $<2$ ) & $2.50(1.65-3.78)$ & $<0.001$ & $2.32(1.37-3.92)$ & 0.002 \\
\hline Smoke status (Y vs. N) & $1.36(0.96-1.91)$ & 0.08 & & \\
\hline Tumor Stage (IV vs. III) & $1.60(1.21-2.13)$ & 0.001 & $1.56(1.14-2.12)$ & 0.005 \\
\hline Histology (non-AC vs. AC) & $1.37(1.07-1.77)$ & 0.013 & $1.37(1.02-1.82)$ & 0.034 \\
\hline EGFR Status (WT vs. MT) & $2.32(1.15-4.67)$ & 0.020 & $2.83(1.14-7.01)$ & 0.025 \\
\hline Neutrophilia (Y vs. N) & $1.67(1.30-2.15)$ & $<0.001$ & & \\
\hline Lymphocytopenia (Y vs. N) & $1.16(0.86-1.57)$ & 0.319 & & \\
\hline NLR $(\geq 3.7$ vs. $<3.7)$ & $1.74(1.32-2.28)$ & $<0.001$ & $1.74(1.26-2.41)$ & $<0.001$ \\
\hline $\begin{array}{l}\mathrm{AC}=\text { Adenocarcinoma } ; \mathrm{C} \\
\text { Performance Status } ; \mathrm{EG} \\
\mathrm{M}=\text { male } \mathrm{MT}=\text { mutate }\end{array}$ & $\begin{array}{l}\text { nce interval; ECC } \\
\text { lermal growth fac } \\
\text { JLR = Neutrophil }\end{array}$ & $\begin{array}{l}\mathrm{PS}=\text { Eas } \\
\text { receptor; } \\
\text { ymphocy }\end{array}$ & $\begin{aligned} & \text { Cooperative Onco } \\
&= \text { female; } \mathrm{HR}=\text { haze } \\
& \text { ratio; } \mathrm{WT}=\text { wild-ty }\end{aligned}$ & $\begin{array}{l}\text { y Group } \\
\text { ratio; } \\
\text { status }\end{array}$ \\
\hline
\end{tabular}

liver metastases [15], bladder cancer [16], malignant mesothelioma [17], ovarian cancer [18] and renal cell carcinoma [19-22].

The aim of this study was to assess the prognostic role of pre-treatment neutrophilia, lymphocytopenia and NLR and to design a model to define the prognosis of patients receiving first-line chemo- or targeted therapy for advanced NSCLC.

\section{RESULTS}

\section{Patient characteristics}

Five hundreds and twenty-one patients were treated with first-line therapies. Of these, 401 patients ( 275 males and 126 female) were included in the NLR analysis, while 120 patients were excluded for the lack of data on pretreatment NLR.

The median age was 68y (range 25-86). The majority were current or former smokers ( 323 patients, $81 \%$ ). Histology was adenocarcinoma in 258 patients (64\%), squamous carcinoma in 94 patients $(23 \%)$ and other histology in 49 patients $(13 \%)$. One hundred and twenty-one (30\%) patients have stage III and 280 patients $(70 \%)$ has stage IV disease. First-line therapy involved chemotherapy in 373 patients (93\%) and EGFRTKIs in 28 patients (7\%). The complete list of patients' characteristics is summarized in Table 1.

The median neutrophil count was $7020 / \mathrm{mm}^{3}$, median lymphocyte count was $1400 / \mathrm{mm}^{3}$ and median NLR was 5.1. Absolute neutrophilia $\left(\geq 7500 / \mathrm{mm}^{3}\right)$ was present in 179 patients $(45 \%)$, while lymphocytopenia (< $\left.1500 / \mathrm{mm}^{3}\right)$ was reported in 87 patients $(22 \%)$.

The best NLR cut-off was $\geq 3.7$ vs. $<3.7$, as identified by ROC curve analysis (Figure 1). Patients were further divided into two groups according to NLR. Two hundred and sixty-four patients (66\%) had NLR $\geq 3.7$ at baseline (Group A), while 137 (34\%) had lower NLR (Group B).

\section{Overall survival (OS)}

The median OS from first-line therapy was 14.4 months (95\% CI 12.4 to 16.9) in the total population. Two hundred and forty eight patients died during follow-up.

The median OS was 19.6 months (95\% CI 16.5 to $28.6)$ in the 78 non-smokers and 13.1 months $(95 \% \mathrm{CI}$ 10.8 to 16.0$)$ in the 323 smokers $(p=0.08)$. Stratified by gender, the median OS was 11.7 months (95\% CI 9.5 to $15.5)$ in males and 18.4 months (95\% CI 14.4 to 27.9$)$ in females $(p=0.005)$. No significant difference was 
found between patients aged $<70 \mathrm{y}$ vs. $\geq 70 \mathrm{y}$ (14.7 vs. 14.4 months, $p=0.335)$. Patients with ECOG-PS $\geq 2$ had a significantly shorter OS compared to those with ECOG-PS $<2$ (4.6 vs. 15.5 months, $p<0.001$ ).

With respect to histology, the median OS was 11.9 months (95\% CI 9.5 to 15.5$)$ in patients with squamous carcinoma, 16.2 months (95\% CI 13.4 to 22.0) for adenocarcinoma and 12.7 months (95\% CI 9.6 to 16.8$)$ for other histologies $(p=0.053)$.

The median OS was 9.7 months (95\% CI 7.4 to 14.4) and 16.9 months (95\% CI 14.4 to 20.6) for patients with and without absolute neutrophilia, respectively $(p<$ 0.001) (Figure 2A). No significant difference was found between patients with and without lymphocytopenia (13.7 vs. 14.5 months, $p=0.319$ ).

Stratified by NLR $\geq 3.7$ vs. $<3.7$, the median OS

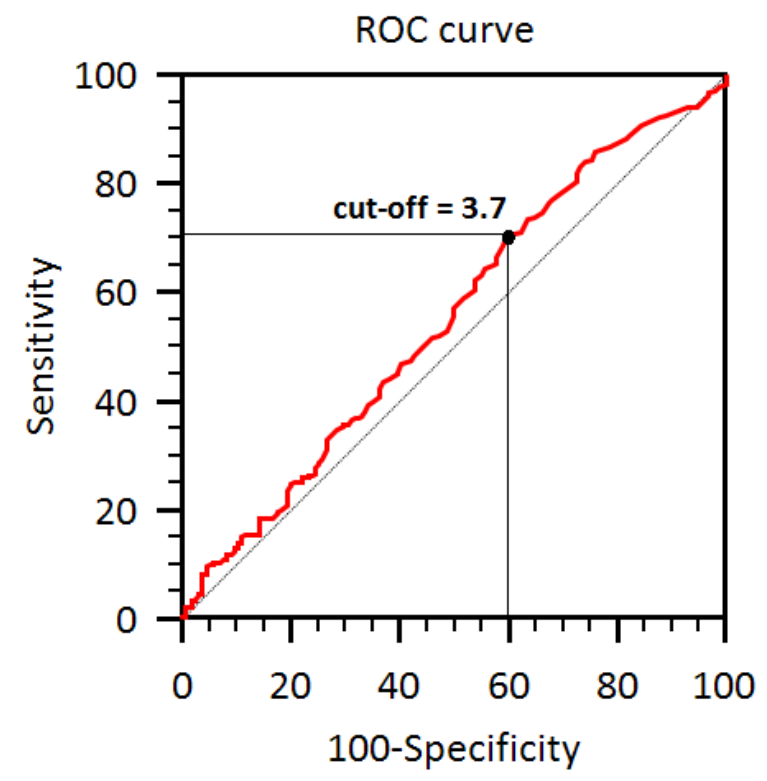

Figure 1: Cut-off identification by ROC curve.

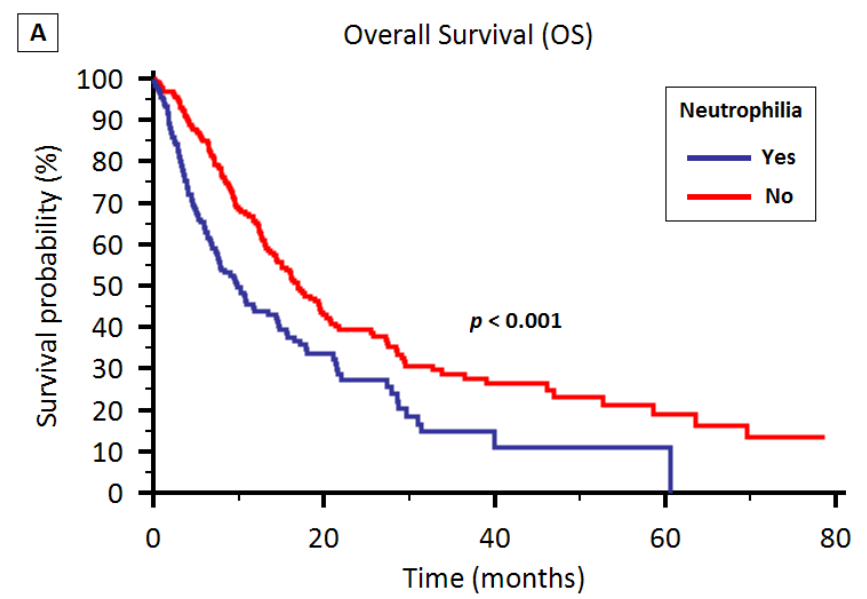

was 10.8 months (95\% CI 9.3 to 14.7$)$ in Group A and 19.4 months (95\% CI 15.0 to 29.1$)$ in Group B $(p<0.001)$ (Figure 3A).

Univariate analysis showed that gender (male), ECOG-PS $\geq 2$, current or former smokers, tumor stage IV, non-adenocarcinoma histology, wild-type EGFR status, neutrophilia and NLR $\geq 3.7$ were significantly associated with worse OS (Table 2). At multivariate analysis, ECOGPS, tumor stage, histology, EGFR status and NLR were predictors of OS (Table 2).

\section{Progression-free survival (PFS) and response to first-line therapy}

The median PFS was 4.1 months (95\% CI 3.6 to $4.8)$ in the overall study population, 3.7 months (95\% CI 3.3 to 4.4$)$ in males and 5.4 months $(95 \%$ CI 4.4 to 6.9$)$ in females $(p=0.04)$.

The median PFS was 5.8 months (95\% CI 3.9 to 8.7$)$ in the 78 non-smokers and 4.1 months (95\% CI 3.6 to 4.8$)$ in the 323 smokers $(p=0.08)$. No significant difference was found with respect to age $<70 \mathrm{y}$ vs. $\geq 70 y$ (3.9 vs. 4.2 months, $p=0.945$ ), ECOG-PS $\geq 2$ vs. $<2$ (3.7 vs. 4.2 months, $p=0.10$ ), or histology (squamous carcinoma vs. adenocarcinoma vs. other histologies: 3.9 vs. 4.4 vs. 4 months).

Median PFS was 3.6 months (95\% CI 3.2 to 4.4 ) and 4.8 months (95\% CI 3.9 to 5.6) in patients with and without absolute neutrophilia, respectively $(p=0.031)$ (Figure 2B). Similarly to OS, no difference was found between patients with and without lymphocytopenia (3.7 vs. 4.2 months, $p=0.42$ ).

Stratified by NLR, the median PFS was 3.6 months (95\% CI 3.2 to 4.2 ) in Group A and 5.6 months (95\% CI 4.6 to 7.4 ) in Group B ( $p=0.012$ ) (Figure 3B).

Furthermore, univariate analysis showed that gender (male), ECOG-PS $\geq 2$, current or former smokers, tumor

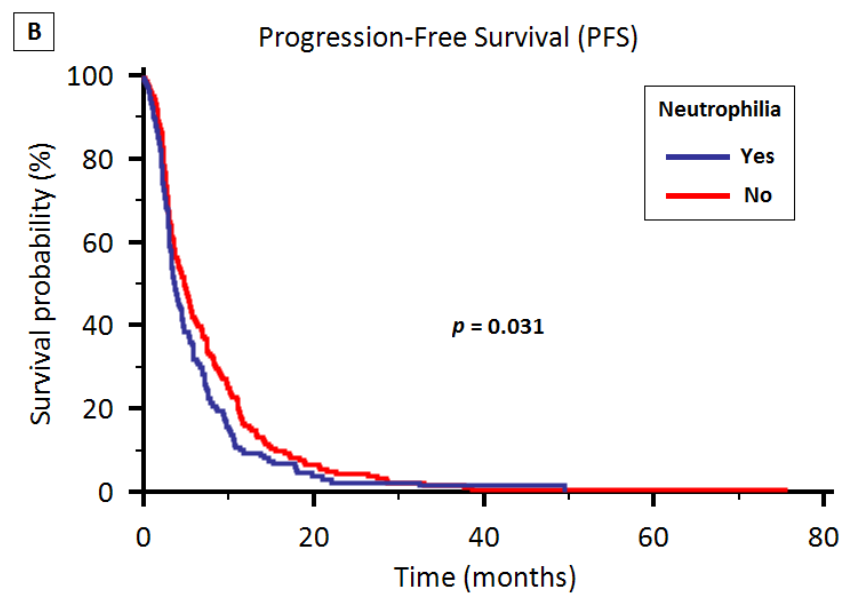

Figure 2: OS (2A) and PFS (2B) stratified by the presence of neutrophilia in patients treated with first-line therapy for locally advanced or metastatic NSCLC. 
Table 3: Univariate and multivariable analysis of predictors of PFS in patients treated with first-line therapy for locally advanced or metastatic NSCLC.

\begin{tabular}{|c|c|c|c|c|}
\hline \multicolumn{5}{|c|}{ PROGRESSION-FREE SURVIVAL } \\
\hline & \multicolumn{2}{|c|}{ Univariate Cox Regression } & \multicolumn{2}{|c|}{ Multivariable Cox regression } \\
\hline & HR $(95 \% C I)$ & p-value & HR $(95 \% C I)$ & p-value \\
\hline Age $(\geq 70 y$ vs. $<70 y)$ & $1.01(0.82-1.24)$ & 0.945 & & \\
\hline Gender (F vs. M) & $0.80(0.64-0.99)$ & 0.043 & & \\
\hline ECOG-PS ( $\geq 2$ vs. $<2)$ & $1.37(0.94-2.00)$ & 0.105 & & \\
\hline Smoke status (Y vs. N) & $1.29(0.97-1.71)$ & 0.083 & & \\
\hline Tumor Stage (IV vs. III) & $1.21(0.97-1.52)$ & 0.09 & $1.33(1.04-1.70)$ & 0.024 \\
\hline Histology (non-AC vs. AC) & $0.96(0.78-1.19)$ & 0.727 & & \\
\hline EGFR Status (WT vs. MT) & $2.47(1.56-3.92)$ & $<0.001$ & $2.67(1.57-4.53)$ & $<0.001$ \\
\hline Neutrophilia (Y vs. N) & $1.25(1.02-1.54)$ & 0.032 & & \\
\hline Lymphocytopenia (Y vs. N) & $1.09(0.85-1.39)$ & 0.518 & & \\
\hline $\operatorname{NLR}(\geq 3.7$ vs. $<3.7)$ & $1.32(1.06-1.64)$ & 0.013 & $1.36(1.04-1.76)$ & 0.023 \\
\hline $\begin{array}{l}\mathrm{AC}=\text { Adenocarcinoma } \mathrm{CI} \\
\text { Performance } \mathrm{Status} ; \mathrm{EGH} \\
\mathrm{M}=\text { male } ; \mathrm{MT}=\text { mutated }\end{array}$ & $\begin{array}{l}\text { ee interval; ECOC } \\
\text { ermal growth facto } \\
\text { LR = Neutrophil t }\end{array}$ & $\begin{array}{l}\text { S = East } \\
\text { eceptor; } 1 \\
\text { ymphocy }\end{array}$ & $\begin{array}{l}\text { Cooperative Oncol } \\
\text { female; } \mathrm{HR}=\text { haza }\end{array}$ & $\begin{array}{l}\text { Group } \\
\text { atio; }\end{array}$ \\
\hline
\end{tabular}

stage IV, wild-type EGFR status, neutrophilia and NLR $\geq$ 3.7 were significantly associated with worst PFS (Table 3). Multivariate Cox regression analysis revealed that tumor stage IV, wild-type EGFR status and NLR $\geq 3.7$ were independent prognostic factors for worse PFS (Table 3).

As for response to first-line therapy, we compared by chi-squared test the rate of disease progressions in patients with NLR $\geq 3.7$ vs. $<3.7$. In the subgroup with higher NLR, the progression rate was $81 \%$ vs $71 \%$ in patients with NLR $<3.7$, showing a significant difference between these two populations $(p=0.03)$.

\section{Prognostic models for OS and PFS}

Based on the multivariate analysis, ECOG-PS, tumor stage, histology, EGFR status and NLR were significantly associated with OS. A prognostic model was therefore created, stratifying patients according to the presence of $0-1$ of these prognostic factor (33 patients, $8 \%$ ), 2-3 factors (293 patients, 73\%) and 4-5 factors (75 patients, 19\%). In the 3 groups, the median OS was 33.7 months (95\% CI 29.5 to N.A.), 14.6 months (95\% CI 12.7 to 17.4 ) and 6.6 months (95\% CI 4.9 to 9.7$)$, respectively $(p<0.001$; Figure 4A).

As a sensitivity analysis, we evaluated our prognostic model also in patients with EGFR wild-type tumors. In this subgroup, OS was 32.8 (95\% CI 28.3 to N.A.), 14.4 (95\% CI 12.2 to 17.4$)$ and 9.7 (95\% CI 4.9 to 11.8 ) months in patients with $0-1,2-3$ or $4-5$ factors, respectively ( $p=0.041$, Figure $\mathrm{S} 1)$.

A similar prognostic model based on the multivariate analysis for PFS was created, with patients stratified on the presence of $0-1$ factor (60 patients, 15\%), 2 factors (166 patients, $41 \%$ ) and 3 factors (175 patients, 44\%). The median PFS was 8.3 months (95\% CI 6.3 to 11.2 ), 4.6 months (95\% CI 3.9 to 5.8$)$ and 3.3 months (95\% CI 3.0 to 3.9$)$, respectively ( $p<0.001$; Figure 4B).

\section{DISCUSSION}

A better understanding of the complexity of tumor-immune interactions in patients with NSCLC has facilitated an increased interest and development of immune therapeutic strategies. However the effects of chemotherapy and targeted agents on the immune system and its role in tumour response to therapies remains less clear.

Previous groups have examined pre-treatment NLR in NSCLC. In early-stage disease, NLR was positively associated with the prognosis for patients treated with stereotactic radiation [23] and surgery [24-26]. Zhang et al. showed that preoperative lymphocytopenia correlated with lymphatic invasion and a shorter disease-free survival (DFS, 318 vs. 669 days) in 142 patients with NSCLC who underwent lobectomy and lymph node dissection and adjuvant chemotherapy. Neutrophil count however was 
not associated with DFS [27]. Elevated pre-treatment NLR was significantly associated with worse OS in 81 advanced EGFR-mutated NSCLC patients treated with first-line EGFR TKIs [28], as well as in 199 never smokers with advanced NSCLC receiving gefitinib or standard chemotherapy [29]. In addition, Yao et al. found that high NLR was associated with shorter OS and PFS in patients with advanced NSCLC treated with first-line platinumbased chemotherapy [30]. More recently, three different meta-analyses have confirmed the prognostic role of NLR in patients with lung cancer [31-33].

To the best of our knowledge, this is the largest study investigating for the role of neutrophilia, lymphocytopenia and NLR in patients with NSCLC treated with first-line therapies. In our study, ECOG-PS $\geq 2$, IV tumor stage, non-adenocarcinoma histology, EGFR wild-type status and NLR were predictors of worse OS, whilst tumor stage IV, wild-type EGFR status and NLR $\geq 3.7$ were independent prognostic factors for worse PFS. Based on these data, we designed two prognostic models for OS and PFS. Median OS differed according to the presence of 0-1, 2-3 or 4-5 prognostic factors, thus identifying patients with good, intermediate and poor prognosis (33.7 months vs. 14.6 months vs. 6.6 months, $p<0.001)$. Similarly, when patients were stratified according to the presence of $0-1,2$ or 3 prognostic factors for PFS, different duration of response to first-line therapies became evident (8.3 months vs. 4.6 months vs. 3.3 months, $p<0.001$ ).

There are some limitations to this study. First, this is a retrospective study, which is susceptible to bias in data selection and analysis. Other inflammatory markers such as C-reactive protein (CRP) or procalcitonin, are not routinely measured in our institutions and so were not included. Furthermore, NLR differs among individuals and can present fluctuations due to concurrent infections and other medications, factors that cannot be fully accounted for in this study. Moreover, some patients (13/41) with EGFR mutated tumors were not treated with EGFR-TKIs
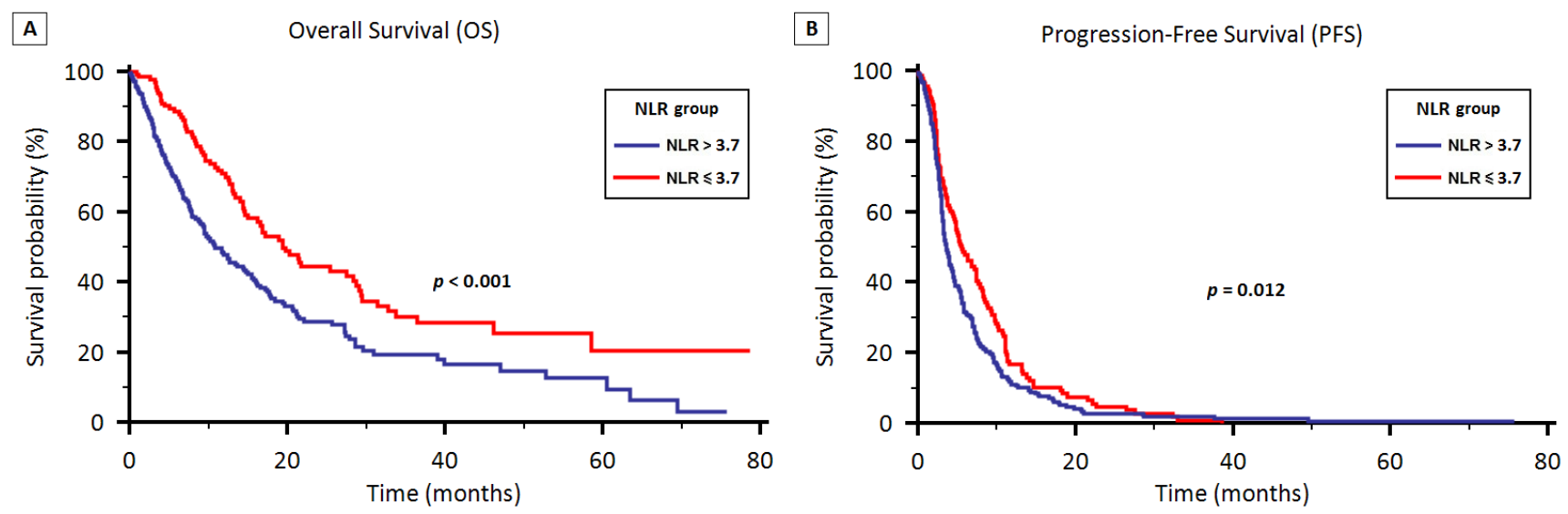

Figure 3: OS (3A) and PFS (3B) stratified by neutrophil to lymphocyte ratio (NLR) in patients treated with first-line therapy for locally advanced or metastatic NSCLC.
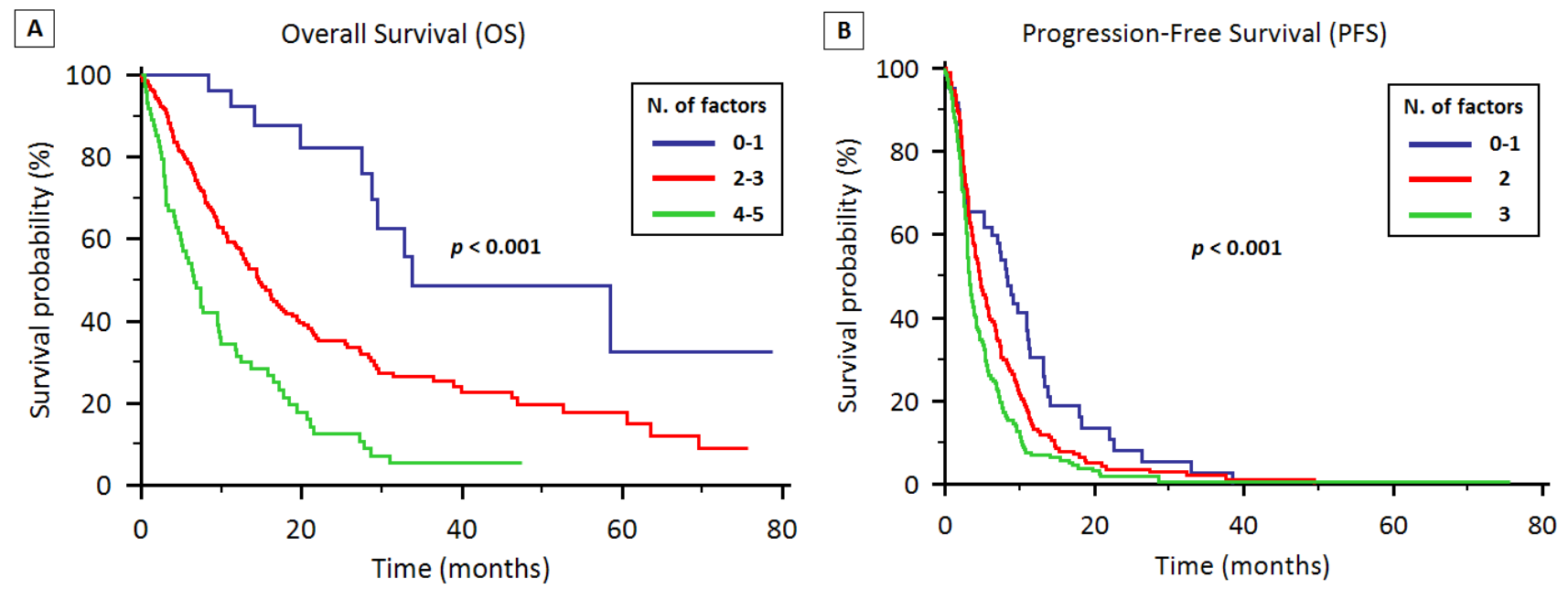

Figure 4: Prognostic models for OS (4A) and PFS (4B) in patients treated with first-line therapy for locally advanced or metastatic NSCLC. 
as first-line therapy due to unavailable data on EGFR mutational status at time of the beginning of treatment.

Despite these limitations, our study suggests that pre-treatment NLR is associated with PFS and OS in patients treated with first-line therapies for advanced NSCLC. Prospective studies are needed to evaluate and validate the prognostic models described here and adequately assess the potential role of NLR in guiding treatment decisions, patient selection, and clinical trials design.

\section{MATERIALS AND METHODS}

\section{Study population and data collection}

The study population was adults with a histological or cytological diagnosis of locally advanced or metastatic NSCLC treated with first-line chemotherapy or targeted therapy according to EGFR mutational status at two institutions (Università Politecnica Marche, Italy and Chelsea \& Westminster Hospital, UK) between $1^{\text {st }}$ May 2009 and 31th October 2014. Tumor stages were assessed according to the tumor-node-metastasis (TNM) criteria and included patients with stage IIIB and IV, as well as patients in stage IIIA not suitable for surgery, as defined in AJCC version 7 [34].

Patients were ineligible if they had received surgery or radiotherapy within one month from the start of firstline therapy and if they presented factors that could influence NLR (see below). Data was retrospectively collected from patients' medical records.

Treatment with first-line chemotherapy or TKIs was continued until evidence of disease progression on scans, unacceptable adverse events, or death. Followup generally consisted of regular physical examination and laboratory assessment (hematologic and serum biochemical measurements), and imaging studies by computed tomography (CT) or magnetic resonance imaging (MRI) scans was carried out according to local procedures every 8-12 weeks.

The OS was defined as the time from the beginning of first-line treatment until death from any cause. Progression free survival (PFS) was defined as the time from beginning of treatment to disease progression or death from any cause. Patients without tumour progression or death at the time of the data cut-off for the analysis or at the time of receiving an additional anticancer therapy were censored at their last date of adequate tumour evaluation.

Peripheral blood samples were obtained 1 to 7 days before the start of first-line therapy. Patients without available data on pre-treatment NLR and those with baseline comorbidities that might influence NLR, such as chronic lymphocytic leukaemia (CLL), chronic inflammatory diseases, and recent signs of infection or therapy with steroids or granulocyte colony stimulating factor (G-CSF), were excluded.

\section{Statistical analysis}

PFS and OS were estimated using Kaplan-Meier method with Rothman's 95\% confidence intervals (CI) and compared across the groups using the log-rank test. Patients with a stable disease (SD), partial remission, and a complete remission were considered as responders.

Pre-treatment NLR was calculated by dividing the absolute neutrophil count by the absolute lymphocyte count and potential factors associated with outcome were evaluated, including patients' age ( $\geq 70 \mathrm{y}$ vs. $<70 \mathrm{y})$, gender, tumor stage, histology, EGFR mutational status, Eastern Cooperative Oncology Group-Performance Status (ECOG-PS), smoking history, neutrophil count, lymphocyte count, and NLR. We determined by ROC analysis the value that best discriminated between good and poor survival.

Cox proportional hazards models were applied to explore patients' characteristics predictors of survival in univariate- and multivariable analysis. Variables not fitting at univariate analysis were excluded from the multivariate model. No-multicollinearity of the grouped co-variates was checked. Significance level in the univariate model for inclusion in the multivariate final model was more liberally set at a 0.2 level, according to Hosmer et al. $[35,36]$. The likelihood ratio test was conducted to evaluate the improvement in prediction performance gained by backward elimination of variables from the prognostic model [37]. All other significance levels were set at a 0.05 value and all $P$ values were two-sided. Statistical analyses were performed using MedCalc version 11.4.4.0 (MedCalc Software, Broekstraat 52, 9030 Mariakerke, Belgium).

\section{ACKNOWLEDGMENTS}

This research did not receive any specific grant from any funding agency in the public, commercial or not-forprofit sector. The study was realized with solely funding from Università Politecnica delle Marche, Ancona Italy.

\section{CONFLICTS OF INTEREST}

All authors disclose no financial and personal relationships with other people or organizations that could inappropriately influence their work.

All authors declare that have not received fees for serving as a speakers or consultants and/or an advisory board members for any organizations. All authors have no received research funding from any organizations. No authors are employees of any organization. No authors own stocks and/or shares in organization. No authors own patent. 
All authors declare that they have no competing interests.

All authors contributed to the editorial, read and approved the final manuscript.

Disclose any potential conflicts of interest.

\section{GRANT SUPPORT}

No grants, equipment, drugs, and/or other support facilitated conduct of the work described in the article or the writing of the article itself.

\section{REFERENCES}

1. Siegel R, Naishadham D, Jemal A. Cancer statistics, 2013. CA Cancer J Clin 2013;63:11-30.

2. Tanvetyanon T, Finley DJ, Fabian T, Riquet M, Voltolini L, Kocaturk C, Bryant A, Robinson L. Prognostic Nomogram to Predict Survival after Surgery for Synchronous Multiple Lung Cancers in Multiple Lobes. J Thorac Oncol 2015;10: 338-345.

3. Guerrera F, Errico L, Evangelista A, Wilsgaard T, Bremnes RM, Busund LT, Donnem T. Exploring Stage I non-smallcell lung cancer: development of a prognostic model predicting 5-year survival after surgical resection. Eur J Cardiothorac Surg 2014;18(suppl 1). DOI: 10.1093/ejcts/ ezu410.

4. van der Pijl LL, Birim O, van Gameren M, Kappetein AP, Maat APWM, Steyerberg EW, Bogers AJCC. Validation of a prognostic model to predict survival after non-small-cell lung cancer surgery. Eur J Cardiothorac Surg 2010;38:6159.

5. Hoang T, Dahlberg SE, Sandler AB, Brahmer JR, Schiller JH, Johnson DH. Prognostic models to predict survival in non-small-cell lung cancer patients treated with first-line paclitaxel and carboplatin with or without bevacizumab. J Thorac Oncol. 2012;7:1361-8.

6. Dehing-Oberije C, Aerts H, Yu S, De Ruysscher D, De Ruysscher D, Menheere P, Hilvo M, van der Weide H, Rao B, Lambin P. Development and validation of a prognostic model using blood biomarker information for prediction of survival of non-small-cell lung cancer patients treated with combined chemotherapy and radiation or radiotherapy alone (NCT00181519, NCT00573040, and NCT00572325). Int J Radiat Oncol Biol Phys. 2011;81:360-8.

7. Skillrud DM, Offord KP, Miller RD. Higher risk of lung cancer in chronic obstructive pulmonary disease. A prospective, matched, controlled study. Ann Intern Med 1986; 105:503-507.

8. Baron JA, Sandler RS. Nonsteroidal anti-inflammatory drugs and cancer prevention. Annu Rev Med 2000, 51:51123.

9. Hattar K, Franz K, Ludwig M, Sibelius U, Wilhelm J, Lohmeyer J, Savai R, Subtil FS, Dahlem G, Eul B,
Seeger W, Grimminger F, Grandel U. Interactions between neutrophils and non-small cell lung cancer cells: enhancement of tumor proliferation and inflammatory mediator synthesis. Cancer Immunol Immunother. 2014;63:1297-306.

10. Rotondo R, Barisione G, Mastracci L, Grossi F, Orengo AM, Costa R, Truini M,Fabbi M, Ferrini S, Barbieri O. IL- 8 induces exocytosis of arginase 1 by neutrophil polymorphonuclears in nonsmall cell lung cancer. Int $\mathrm{J}$ Cancer. 2009;125:887-93.

11. Teramukai S, Kitano T, Kishida Y, Kawahara M, Kubota K, Komuta K, Minato K, Mio T, Fujita Y, Yonei T, Nakano K, Tsuboi M, Shibata K, Furuse K, Fukushima M. Pretreatment neutrophil count as an independent prognostic factor in advanced non-small-cell lung cancer: an analysis of Japan Multinational Trial Organisation LC00-03.Eur J Cancer. 2009;45:1950-8.

12. Yamanaka $\mathrm{T}$, Matsumoto $\mathrm{S}$, Teramukai $\mathrm{S}$, Ishiwata $\mathrm{R}$, Nagai Y, Fukushima M. The baseline ratio of neutrophils to lymphocytes is associated with patient prognosis in advanced gastric cancer. Oncology 2007;73: 215-220.

13. An X, Ding PR, Li YH, Wang FH, Shi YX, Wang ZQ, He YJ, Xu RH, Jiang WQ. Elevated neutrophil to lymphocyte ratio predicts survival in advanced pancreatic cancer. Biomarkers 2010;15: 516-522.

14. Gomez D, Farid S, Malik HZ, Young AL, Toogood GJ, Lodge JP, Prasad KR. Preoperative neutrophil-tolymphocyte ratio as a prognostic predictor after curative resection for hepatocellular carcinoma. World J Surg 2008;32: 1757-1762.

15. Kishi Y, Kopetz S, Chun YS, Palavecino M, Abdalla EK, Vauthey JN. Blood neutrophil-to-lymphocyte ratio predicts survival in patients with colorectal liver metastases treated with systemic chemotherapy. Ann Surg Oncol 2009;16: 614-622.

16. Rossi L, Santoni M, Crabb SJ, Scarpi E, Burattini L, Chau C, Bianchi E, Savini A, Burgio SL, Conti A, Conteduca V, Cascinu S, De Giorgi U. High Neutrophil-to-lymphocyte Ratio Persistent During First-line Chemotherapy Predicts Poor Clinical Outcome in Patients with Advanced Urothelial Cancer. Ann Surg Oncol. 2015;22:1377-84.

17. Kao SC, Pavlakis N, Harvie R, Vardy JL, Boyer MJ, van Zandwijk N, Clarke SJ. High blood neutrophil-tolymphocyte ratio is an indicator of poor prognosis in malignant mesothelioma patients undergoing systemic therapy. Clin Cancer Res 2010;16: 5805-5813.

18. Cho H, Hur HW, Kim SW, Kim SH, Kim JH, Kim YT, Lee K. Pre-treatment neutrophil to lymphocyte ratio is elevated in epithelial ovarian cancer and predicts survival after treatment. Cancer Immunol Immunother 2009;58:15-23.

19. Ohno Y, Nakashima J, Ohori M, Gondo T, Hatano T, Tachibana M. Follow up of neutrophil-to-lymphocyte ratio and recurrence of clear cell renal cell carcinoma. J Urol 2012;187:411417. 
20. Ohno Y, Nakashima J, Ohori M, Hatano T, Tachibana M. Pretreatment neutrophil-to-lymphocyte ratio as an independent predictor of recurrence in patients with nonmetastatic renal cell carcinoma. J Urol 2010;184:873878.

21. Keizman D, Ish-Shalom M, Huang P, Eisenberger MA, Pili R, Hammers H, Carducci MA. The association of pretreatment neutrophil to lymphocyte ratio with response rate, progression free survival and overall survival of patients treated with sunitinib for metastatic renal cell carcinoma. Eur J Cancer 2012;48:202208.

22. Santoni M, De Giorgi U, Iacovelli R, Conti A, Burattini L, Rossi L, Luca Burgio S, Berardi R, Muzzonigro G, Cortesi E, Amadori D, Cascinu S. et al. Pre-treatment neutrophilto-lymphocyte ratio may be associated with the outcome in patients treated with everolimus for metastatic renal cell carcinoma. Br J Cancer 2013;109:1755-9.

23. Cannon NA, Meyer J, Iyengar P, Westover KD, Choy H, Timmerman R.Neutrophil-lymphocyte and plateletlymphocyte ratios as prognostic factors following stereotactic radiation therapy for early-stage non-small cell lung cancer. J Thorac Oncol 2015;10:280-5

24. Tomita M, Shimizu T, Ayabe T, Yonei A, Onitsuka T. Preoperative neutrophil to lymphocyte ratio as a prognostic predictor after curative resection for non-small cell lung cancer. Anticancer Res. 2011;31:2995-8.

25. Pinato DJ, Shiner RJ, Seckl MJ, Stebbing J, Sharma R, Mauri FA. Prognostic performance of inflammation-based prognostic indices in primary operable non-small cell lung cancer. Br J Cancer. 2014;110:1930-5.

26. Tomita M, Shimizu T, Ayabe T, Nakamura K, Onitsuka $\mathrm{T}$. Elevated preoperative inflammatory markers based on neutrophil-to-lymphocyte ratio and $\mathrm{C}$-reactive protein predict poor survival in resected non-small cell lung cancer. Anticancer Res. 2012;32:3535-8.

27. Zhang J1, Huang SH, Li H, Li Y, Chen XL, Zhang WQ, Chen $\mathrm{HG}, \mathrm{Gu}$ LJ. Preoperative lymphocyte count is a favorable prognostic factor of disease-free survival in nonsmall-cell lung cancer. Med Oncol. 2013;30:352.

28. Lin GN, Peng JW, Liu PP, Liu DY, Xiao JJ, Chen XQ. Elevated neutrophil-to-lymphocyte ratio predicts poor outcome in patients with advanced non-small-cell lung cancer receiving first-line gefitinib or erlotinib treatment. Asia Pac J Clin Oncol 2014 doi: 10.1111/ajco.12273.
29. Lee Y, Kim SH, Han JY, Kim HT, Yun T, Lee JS. Early neutrophil-to-lymphocyte ratio reduction as a surrogate marker of prognosis in never smokers with advanced lung adenocarcinoma receiving gefitinib or standard chemotherapy as first-line therapy. J Cancer Res Clin Oncol 2012;138:2009-16.

30. Yao Y, Yuan D, Liu H, Gu X, Song Y. Pretreatment neutrophil to lymphocyte ratio is associated with response to therapy and prognosis of advanced non-small cell lung cancer patients treated with first-line platinum-based chemotherapy. Cancer Immunol Immunother. 2013;62:4719.

31. Zhao QT, Yang Y, Xu S, Zhang XP, Wang HE, Zhang H, Wang ZK, Yuan Z, Duan GC. Prognostic role of neutrophil to lymphocyte ratio in lung cancers: a meta-analysis including 7,054 patients. Onco Targets Ther 2015;8:2731-8.

32. Yin Y, Wang J, Wang X, Gu L, Pei H, Kuai S, Zhang Y, Shang Z. Prognostic value of the neutrophil to lymphocyte ratio in lung cancer: A meta-analysis. Clinics (Sao Paulo) 2015;70:524-30.

33. Gu XB, Tian T, Tian XJ, Zhang XJ. Prognostic significance of neutrophil-to-lymphocyte ratio in non-small cell lung cancer: a meta-analysis. Sci Rep 2015;5:12493.

34. Edge SB, Compton CC. The American Joint Committee on Cancer: the 7th edition of the AJCC Cancer Staging Manual and the future of TNM. Ann Surg Oncol 2010;17:14711474

35. Fagerland MW, Hosmer DW, Bofin AM. Multinomial goodness-of-fit tests for logistic regression models. Stat Med 2008;27:4238-4253.

36. Mickey RM, Greenland S. The impact of confounder selection criteria on effect estimation. Am J Epidemiol 1989;129:125-137.

37. Pepe MS, Kerr KF, Longton G, Wang Z. Testing for improvement in prediction model performance. Stat Med. $2013 ; 32: 14671482$. 